\title{
4. Schluß
}

Weit ist das Feld des Realismus. Sollte man es nicht unübersichtlich nennen? Mit Gewißheit erkennen läßt sich, daß der Realismus zwar die alltägliche, aber nicht jede beliebige, sondern am liebsten die reigentliche Wirklichkeit ins Auge faßt. Seine Botschaft heißt nicht einfach 'gesehenes Leben`, sondern streffender Sinn`; der aber steht nicht als 'Gesetz، starr im Bilde, sondern 'verschwimmt ' eher am Horizont, jedenfalls bleibt er in Bewegung. Denn was der Realismus wesentlich sieht, sieht er nur von weitem. Und so steht er tatsächlich auf weitem Feld, wo er gute Instrumente braucht, um von möglichst verschiedenen Seiten aus die 'Früchte seiner Wirklichkeit` einschätzen zu können. Nicht um Registrierung oder Abbildung seiner 'Rohstoffer geht es ihm, sondern um deren Verarbeitung, um eine IInszenierung, die selbst das Phantastische nicht scheut, wenn es gilt, innerhalb der Bannmeile frappierender Wirklichkeitseffekte das tolle Spiel mit tausend Finessen dezent anzudeuten. Insofern sind realistische Darstellungen trotz aller Einwendungen gegen ihren Wirklichkeitsbezug keine sleeren Bilder`, sondern prall volle. Nüchterner formuliert und nur als Frage aufgeworfen: Wenn sich, Realismus` in eine Gleichung fassen ließe, wäre es dann denkbar, daß gerade jene Position, von der auf den ersten Blick so viel abhängt, also die Realität, wider Erwarten und doch konsequenterweise wegkürzbar sei? 